\title{
Encontros da vida nua nos jardins do capital. Uma investigação sobre o consumo de tratamentos
}

\section{Naked life encounters in the gardens of capital. An investigation into the consumption of treatments}

\author{
Donati Canna Caleri* \\ Universidade Federal Fluminense - UFF, Niterói, Rio de Janeiro, Brasil \\ Claudia Abbês Baêta Neves** \\ Universidade Federal Fluminense - UFF, Niterói, Rio de Janeiro, Brasil
}

\begin{abstract}
RESUMO
Este artigo discute a medicalização da vida, no contemporâneo, com o foco nas ações de cuidado em saúde, problematizando o processo crescente de medicalização da existência e da naturalização do consumo de terapias, tratamentos e tutelas. Este processo atualiza uma das facetas dos processos de expansão e acumulação do funcionamento capitalista contemporâneo em suas estratégias microfísicas de controle e modulação da vida encarnadas nas práticas de cuidado. Analisamos este foco na emergência e entrecruzamento de dois vetores-força, a medicina e a psicanálise, que em nosso entendimento se hegemonizaram e recobriram as práticas de cuidado da saúde em seus aspectos biológicos e psíquicos. Partindo destas reflexões buscamos pensar a construção de linhas de fuga no fazer clínico que viabilizem modos autônomos do cuidar de si e de construção de mundo.

Palavras-chave: medicalização, consumo, tratamentos, dependência, autonomia.
\end{abstract}

\begin{abstract}
This article discusses contemporary life medicalization, bringing into focus health care actions that question the growing process of medicalization of existence and naturalization of therapies, treatments and care consumption. This process updates one of the aspects of the processes of expansion and accumulation of contemporary capitalist functioning in their microphysical strategies of life control and modulation manifested in care practices. We analyze this focus on the emergency and interweaving of two force vectors, medicine and psychoanalysis, which, in our understanding, have prevailed and pervaded health care practices in both biological and psychic aspects. Based on such reflections, we searched to create creepages in clinical practices aiming at self care and world-building.
\end{abstract}

Keywords: life medicalization, consumption, treatments, dependence, autonomy.

\section{Introdução}


A temática da medicalização da vida, inicialmente esboçada por Illich $(1975)^{1}$, visava problematizar a extensão do raio de ação da medicina através de seu complexo médico-industrial nas sociedades modernas e seus efeitos no comprometimento da autonomia dos homens em relação às suas dores e modos de vida. Ao apontar para a submissão da sociedade as competências técnicas e expertises, oriundas deste complexo tecnológico que lhes dá suporte, o supracitado autor evidenciou os efeitos iatrogênicos ${ }^{2}$ produtores de mais doença, tutela e consumo.

Quando falamos de medicalização fazemos referência a este conceito criado por Ivan Illich em meados da década de setenta e as ampliações e retrabalhos, posteriormente, realizados por Michel Foucault (1989, p. 79-99) a partir dos estudos de Canguilhen sobre a "medicina do não-patológico", a psiquiatrização dos anormais (19741975), os estudos sobre biopoder (1974) e a biopolítica (1978) nos anos setenta e oitenta do século passado.

No âmbito deste artigo nos interessa abordar a temática da medicalização da vida no contemporâneo com o foco nas ações de cuidado em saúde problematizando o processo crescente de medicalização da existência e da naturalização do consumo de terapias, tratamentos e tutelas que trazem no seu contexto uma passividade dos gestos, produzindo uma vida sedenta de adereços e simplificações de giro acelerado e descartável. Este processo atualiza uma das facetas dos processos de expansão e acumulação do funcionamento capitalista contemporâneo em suas estratégias microfísicas de controle e modulação da vida encarnadas nas práticas de cuidado.

Nesta compreensão indagamos: Que tipo de vida temos potencializado em nossas intervenções clínicas? Pois, entendemos que, apostar na criação de mundo é problematizar como estamos implicados nesse processo e nosso grau de pertença e autonomia na relação com suas instituições.

Utilizamos como ponto de partida para nossa análise a relação estabelecida entre usuários do sistema de saúde, pública ou privada, e os especialistas da saúde em geral. Essa relação, que aparentemente visa atender necessidades do humano no âmbito da saúde, tem se hegemonizado como uma relação de caráter tutelar que atrofia a manifestação da vida na sua potência auto-produtiva de criação de normatividades frente à infidelidade do meio (Canguilhen, 1990).

Na clínica, nos espaços de sala de aula, em conversas com grupos de amigos e na mídia em geral, são frequentes os relatos que enaltecem esta ou aquela terapia, este ou aquele terapeuta, analista ou "medalhão". Em geral, os relatos vêm acompanhados de frases como: "Desde que meus filhos nasceram que fazem homeopatia", "Desde que me entendo por gente faço análise", "Não posso deixar 
de fazer 'tal tratamento' ou tomar determinado medicamento", "É muito importante se tratar e querer se tratar", "Você deve procurar um especialista no seu problema". Percebemo-nos muitas vezes perguntando: "Como é que conseguíamos viver antes daquela maravilhosa descoberta médica? Daquele novo remédio? Daquela nova terapia?".

Estas demandas/enunciações que cotidianamente aparecem na clínica, assim como as reações de surpresa quando problematizamos a naturalização destas questões, nos levaram a construir como questão-problema de investigação as perguntas: como se produziu esta demanda de cuidado-tutela para a vida? Quais as forças e vetores que se agenciam nesta produção contemporânea?

Partindo de nossas experiências como psicólogos, no campo da clínica e da formação em saúde, analisamos as práticas de produção de tutela no cuidado na emergência e entrecruzamento de dois vetoresforça, a medicina e a psicanálise, que em nosso entendimento se hegemonizaram e recobriram as práticas de cuidado da saúde em seus aspectos biológicos e psíquicos. Vetores-força aqui entendidos como práticas de saber/poder produtoras de racionalidades que, em seus entrelaçamentos aos modos de subjetivação, sustentam a (re)produção contínua da ordem capitalista.

Nesta compreensão, a medicina e a psicanálise são aqui pensadas como movimentos que, em suas diferenças, se atravessam e constroem um modo de produzir cuidado em saúde orientado, muitas das vezes, a partir de uma lógica biopolítica de consumo e produção de dependência. Sob o signo de uma ciência régia que se erige em supostos modelos estáveis, produz-se uma ampliação e objetivação do cuidado no qual não só os usuários são objetos de uma prática tecnocrática ou de um sistema de saúde normalizador, mas os próprios profissionais quando perdem a capacidade de refletir sobre suas práticas e sua história.

\section{Da Gênese da dependência: capitalismo, controle e biopolítica}

No aspecto molar, o que significa dizer, sua forma visível, o capitalismo se constituiu como modo de produção a partir da conjugação de fatores como: o trabalho livre; os processos remanescentes da decadência do sistema feudal de produção; o monopólio dos meios de produção; a acumulação de riqueza; a produção de mercadorias; a mais-valia; o lucro e o consumo. Estes aspectos poderiam ser elencados como os aspectos visíveis do capitalismo expressos em suas instituições, relações capital-trabalho e enunciados. O que vamos percebendo é que, desde a sua emergência, o capitalismo irá ligar-se no vivo para daí extrair 
materialidade (formas-sujeito, objetos, instituições). A produção de riqueza material sempre esteve conjugada, de algum modo, a processos imateriais (fruição das potências intensivas constituintes do vivo) para produzir modos de ser modelados, subjetivações serializadas, estilos de vida.

Contudo, nesta organização primeira do capitalismo monopolista, verificamos que ele irá se expandir, predominantemente, através do que poderíamos chamar de uma 'lógica extensiva', ou seja, a conquista de territórios, visibilidade, espaços geográficos do planeta.

A partir das conquistas territoriais, conseguidas através de lutas, embates e subsunção de forças divergentes, ele segue, cada vez mais potente, e hoje ganha sobrevida numa reestruturação da organização produtiva que passa a investir, sobretudo numa 'lógica de expansão intensiva', via capital financeiro virtualizado. Então sai do chão, 'alça vôo' e 'pega carona' nos processos moleculares, invisíveis, linhas de subjetivações, como mencionamos anteriormente.

\section{Diagramas de poder e normalização}

Foucault $(1983 ; 1999 ; 2008)$, em sua análise genealógica dos modos de funcionamento do poder no capitalismo, sinaliza que nos diagramas de poder disciplinar e biopolítico as práticas de normalização incidem de diferentes modos na regulamentação da vida.

Nas sociedades de soberania, anteriores ao século XV, a distinção entre os indivíduos e as coisas obedecia a critérios utilitaristas. O direito reservado ao soberano de "fazer morrer e deixar viver" (Foucault, 1999, p.293) é uma das marcas mais expressivas desse tipo de organização social no qual as relações de força descendentes construíam o diagrama político-social da época. Produzia-se uma relação que submetia os súditos, de corpo e alma, à dependência total dos seus senhores.

Em meados do século XVIII, surge o que Foucault (1983) denomina como sociedades disciplinares, cuja emergência rompe com uma concepção de Estado Absoluto, característico das sociedades soberanas, inaugurando um novo tipo de Estado onde o poder é disciplinar. As sociedades disciplinares são marcadas, entre outros aspectos, pela intensificação da produção, circulação de mercadorias e relações de troca. Nessas sociedades, o controle se faz através de uma rede capilarizada que tem como alvo o corpo e sua individualização em aparelhos de normalização.

A escola, o quartel, o hospital, a prisão são espaços disciplinares clássicos, locais onde o mundo do capital produz e dociliza os indivíduos e suas práticas para melhor servi-lo. A normalização disciplinar funciona por meio da produção de modelos-padrão prévios 
que pareados (normal/anormal; certo/errado) instauram normas para os indivíduos em consonância com os regimes de verdade que se querem homogêneos e universais. Assim, o fundamental na normalização disciplinar é a norma, codificando o que é permitido e o que é proibido, incidindo, sobretudo, no que deve ser impedido e naquilo que é obrigatório.

Contudo, do século XIX em diante, o capitalismo, que vinha solidificando sua base territorial extensiva, irá se espraiar pelo planeta, assumindo também formas mais etéreas e intensivas, construindo uma forma de controle constante e ininterrupta. Foucault (1999) atento a este novo funcionamento do diagrama do poder chamava atenção para a emergência de uma nova tecnologia de poder que funciona tomando posse da vida, desde o orgânico ao biológico. Uma tecnologia que fazendo uso do poder-saber como agente de transformação da vida humana inscreve-a no registro da política, a vida como elemento privilegiado no domínio de cálculos explícitos. Ele a denomina de biopolítica e mostra que ela se exerce tomando a população como alvo de regulamentação e de cuidado. Trata-se, aqui, de um exercício de poder que não se faz de fora dos processos, mas em meio a eles. As práticas de normalização no funcionamento biopolítico atuam criando uma nova institucionalidade naquilo que é considerado normal, ou seja, não mais a determinação clara e especifica do que é normal ou anormal, mas a produção de um "quantum funcional" (Foucault, 2008) da sociedade. A função normalizadora institui curvas de normalidade a partir das quais se operam normas, ou seja, constrói-se um dispositivo de controle das subjetividades que se formaliza em meio às séries aleatórias do comportamento humano. Da 'natureza' humana emergem índices que distribuem os modos de vida em categorias menos ou mais favoráveis, concebíveis ou não concebíveis num modo de produção político-econômico capitalista. Nesta perspectiva,

"O normal é que é primeiro, e a norma se deduz dele, ou é a partir desse estudo das normalidades que a norma se fixa e desempenha seu papel operatório (...) não se trata mais de uma normação, mas sim, no sentido estrito, de uma normalização. (Foucault, 2008, p.83)

O controle agora é sobre a totalidade da vida dos indivíduos, numa lógica permanente. Esse período, que se arrasta até o momento atual, é denominado por Deleuze (1992) como sociedade de controle a partir do que Foucault veio cunhar o termo biopolítica.

Apesar de funcionar de modo inverso às antigas tecnologias de poder da soberania, - expressas na vontade e no direito do soberano de "fazer morrer e deixar viver", - e da disciplina, - que rege a multiplicidade dos homens para torná-los individualidades a serem 
controladas, treinadas e vigiadas, o biopoder não as apaga. Ele as conjuga, "penetrando-as, perpassando-as e modificando-as" e, em seu exercício de "fazer viver e deixar morrer" (Foucault, 1999, p.293) toma a vida do homem como ser vivo, como espécie. Este exercício de poder-saber ganha expressão como gestus político-normalizador cujo foco deixa de ser somente a individualidade, como plano molar das formas constituídas, para investir na totalidade da vida, no coletivo. Este, entendido como plano molecular, pré-individual (Escóssia \& Kastrup, 2005) composto por potências impessoais em meio ao qual se faz a produção de subjetividade, em seu constante vir a ser.

Vemos, então, nas sociedades atuais uma sofisticação do controle de tal sorte que não percebemos mais como e quando ele está presente. Contudo, sabemos que está presente, está no ar que respiramos, na água que bebemos, nos sonhos que temos. $O$ controle se metamorfoseou em um gás invisível que penetra todos os espaços do contemporâneo.

\section{A I manência Capitalista}

Negri e Hardt (2001), reafirmando as análises deleuzeanas sobre a sociedade de controle, mostram que os mecanismos de monitoramento do capitalismo no império ${ }^{4}$ são, agora, mais difusos, ondulantes, imanentes e incidem sobre as mentes prescindindo de intermediações institucionais. Eles funcionam através de sistemas de comunicação, redes de informação, atividades de enquadramento e também de mecanismos de interiorização que são reativados pelos próprios sujeitos. Servindo-se de redes flexíveis moduláveis e flutuantes, o poder muda o seu raio de ação, mas também sua extensão, seu alcance e sua penetração. Prolongando a intuição foucaultiana sobre o biopoder, os autores mostram que o exercício de poder agora não é mais restritivo, punitivo e não se exerce primordialmente de modo vertical, mas sob a forma de uma rede horizontal esparramada, entrelaçada ao tecido social e à sua heterogeneidade, articulando singularidades étnicas, religiosas minoritárias, e requerendo, com isto, novas modalidades de controle (Neves, 2002).

Os alimentos, o ar e a água, para citarmos alguns pressupostos básicos de nutrição do humano, estão sendo dizimados por conta da lógica de produção capitalista. Atualmente, grande parte dos alimentos que deveria garantir a saúde e a subsistência do humano encontra-se contaminada, envenenada bem acima do que 0 organismo humano poderia suportar. São agrotóxicos, pesticidas e outros componentes altamente prejudiciais à saúde e à vida, agentes promotores de doença. 
Os venenos são produzidos por empresas nacionais e transnacionais que compõem o capitalismo mundial integrado (Guattari, 1981) e lucram com a sua produção, empregando, de modo precário, inúmeras pessoas. Qualquer ameaça na redução da produção enseja, por parte da direção das empresas, a ameaça de demissão e desemprego. Assim segue o círculo vicioso de produção de doença sem que quase nada possa ser feito para interrompê-lo.

A partir do sucinto quadro traçado acima, sinalizamos o paradoxo, ou melhor, o grande paradoxo que está colocado na área da saúde. Mais ainda, sinalizamos também que estamos num grande "ensaio de cegueira" coletiva, tentando "resolver" problemas de saúde com terapias e tratamentos construídos em meio à lógica do capital, sem efetivamente equivocá-la. Passamos a ver surgir, no campo da saúde, processos intermináveis de adaptação, "amansamento dos conflitos", como dizia Freud, de ajuste a um mundo que produz, com enorme habilidade, doença, vende a doença e lucra com ela.

Esse paradoxo precisa ser pensado, naquilo que Foucault (1985) nos convoca a pensar: "O que estamos ajudando a fazer de nós mesmos"? "O que estamos fazendo dos outros"? (Foucault apud Orlandi, 2002, p. 210).

\section{Vetor I - A Medicina}

Adotamos como acontecimento inaugural que propiciou o surgimento das artes médicas no Ocidente o período em torno do séc. IV e $\mathrm{V}$ a.C., na Grécia, período este em que a racionalidade médica estabelece uma ruptura com a visão xamânica de saúde. Esta visão concebia a doença como um castigo celestial, um mal imposto pelas divindades que, revoltadas com alguma infração ou descumprimento de algum preceito, lançavam a sua ira contra os mortais.

A partir dessa ruptura surge, na cultura e na filosofia grega présocrática, o conceito de Phýsis, referindo-se à natureza como o campo de desenvolvimento de todos os seres. É atribuído a Hipócrates (460/390 a.C.) o título de pai da medicina, pois foi ele quem reuniu vários textos existentes na época (Corpus Hipocraticum) sobre a arte de conservar a saúde e tratar as doenças.

Devido ao fato de a medicina Ocidental basear-se na cultura Grega, achamos pertinente desenvolver ainda algumas reflexões acerca das personagens gregas. Asclepius, importante figura no campo da cura seria, segundo a mitologia, um mortal, filho de Apolo, que teve como instrutor o centauro Quirón. Apolo tornou-se um mestre exemplar na arte da cura. Higéia e Panacéia são filhas de Asclepius. Higéia expressa a saúde sustentada na força vital, na potência da vida, intrínsecas à natureza e presente em todos os seres. Panacéia 
representa o poder curativo presente nas ervas e em outras substâncias encontradas na natureza.

Com o passar do tempo, em meio às lutas entre as linhas de força que se expressavam no pensamento filosófico da época, as irmãs irão tomar caminhos distintos. A ruptura na complementaridade que as duas ensejam irá trazer diversas consequências para 0 desenvolvimento da medicina, como veremos adiante.

Hermes, outro integrante do campo da saúde, é a divindade grega que rouba a lira de Apolo e, em troca, recebe deste o caduceu, símbolo dos poderes médicos. Ele tem como função original conduzir as almas ao $\mathrm{Hades}^{3}$. Seu poder é hipnotizador e, portanto, atua no subterrâneo, ligado às profundezas e à morte. Assim, ele passa a ser a divindade protetora dos magos, dos bruxos, dos curandeiros, daqueles que possuem conhecimentos sobre o obscuro. Ou seja: daqueles que, através da utilização de ervas e poções mágicas, interferem na natureza, e, mais do que isso, na natureza humana, modificando-a, transformando-a. Higéia e Hipócrates caminharão mais próximos, ao passo que Hermes e Panacéia desenvolverão outra via, constituindo o que, com o decorrer do tempo, poderiam ser consideradas duas visões de saúde que se desdobraram em distintas práticas médicas.

A palavra Pharmakon traduz melhor a combinação de ervas, corantes, veneno e outras substâncias que darão origem aos remédios e que serão manipuladas por Hermes, sob a proteção de Panacéia, bem como por futuros alquimistas e médicos, como Paracelso e Galeno. Na outra via, a "vis medicatrix naturae" o entendimento de saúde e de cura diz respeito a uma virtude própria de cada indivíduo.

A medicina hipocrática original se constitui fundamentalmente de uma fé na ordem universal, na existência de leis naturais que se deve respeitar. O médico hipocrático nada deverá fazer temerariamente, preferindo abster-se a causar algum prejuízo com sua intervenção. Não prejudicar é o primeiro dos seus deveres. Confia-se que os seres vivos, de algum modo, são dotados de defesas naturais e regeneradoras na promoção da saúde e no tratamento das doenças.

\section{A linha intervencionista e a arte do cuidar de si}

Nos séculos I e II da nossa era, surgiu um médico que irá estabelecer um método que se transformará na base da medicina e que será mantido, com variações, até o séc. XVIII. Trata-se de Galeno (130201 d.C.), cuja forma de pensar a saúde, guiado por Pharmakon, trará um novo impulso às artes médicas. Embora se intitulasse hipocrático, sua idéia era prescrever e ministrar várias ervas e substâncias ao doente e deixar que o organismo selecionasse aquilo 
que fosse adequado e necessário. Nesse contexto, vai sendo cada vez mais difundida a ideia de substâncias estranhas ao organismo atuarem visando o seu restabelecimento e, fazendo com que o poder e a força da natureza que habita todos os seres deixassem de ser vistos como a fonte principal de cura.

$\mathrm{Na}$ época de Galeno e, talvez como uma resistência à hegemonia nas artes médicas, surge um movimento que confronta a visão de Panacéia e fortalece a de Higéia: o projeto de apostar no vitalismo, na potência da vida, na arte de cuidar de si.

Assim, passava a fazer parte da educação e dos processos de formação o desenvolvimento da capacidade de escutar e observar a natureza, numa lógica de auto-compreensão e auto-desenvolvimento. Buscavam-se formas de autossuficiência através de práticas de purificação, regimes, meditações, leituras, exercícios físicos moderados e cuidados com a dieta, utilizadas como caminhos para promover a saúde e prevenir as doenças, num exercício de autonomia e independência. Vejamos o que dizia Foucault sobre tal questão:

"De um modo geral, pode-se dizer que até o final do século XVIII a medicina referiu-se muito mais a saúde do que a normalidade; não se apoiava na análise de um funcionamento "regular" do organismo para procurar onde se desviou, o que Ihe causa distúrbio, como se pode restabelecê-lo, referiam-se mais as qualidades de vigor, flexibilidade e fluidez que a doença faria perder e que se deveria restaurar. A prática médica podia, desse modo, conceder grande destaque ao regime, à dietética, em suma, a toda uma regra de vida e alimentação que o indivíduo se impunha a si mesmo. Nessa relação privilegiada da medicina com a saúde se encontrava inscrita a possibilidade de ser médico de si mesmo. (Foucault, 2006, p.38)"

Em sua fase inicial, a prática médica seguia um modelo coerente com o próprio modelo de mundo, onde a concepção dualista de homem e natureza inexistia. Naquele período, os meios para 0 restabelecimento da saúde cabiam a cada indivíduo, que vivia uma relação de inseparabilidade com a natureza. Cada um construía uma ética que afirmava a potência da vida, que o fazia livre do que impedia a expansão de modos de ser autônomos na sua via criativa, cada um tornava-se responsável pela sua própria saúde.

No final do século XIX, porém, a descoberta de fatores patogênicos externos tais como: micróbios, germes e vírus assumiram o papel de principais agentes causadores das doenças. A Microbiologia se desenvolve, assim como a Farmácia e outras especialidades médico/científicas. 
Para cada vírus, um remédio específico deveria ser criado: a vacina, 0 antídoto. Esse movimento, inaugurado no final do século XIX, irá ganhar força com a descoberta do soro anti-rábico por Louis Pasteur (1822-1895), bem como do bacilo causador da tuberculose pelo seu contemporâneo Koch (1843-1910) que, além disso, também descobre e desenvolve uma vacina para combatê-lo.

Diante desse quadro acima descrito, Illich irá desenvolver, em 1975, vasta pesquisa que equivoca a idéia do vírus como agente externo e único causador de todos os males. Ele identifica nos aspectos nutricionais e ambientais amplos fatores determinantes do processo saúde/doença. Vejamos:

"A análise das tendências da morbidade mostra que o meio (noção que inclui o modo de vida) é a primeira determinante do estado de saúde global de qualquer população. A alimentação, as condições de habitação e de trabalho, a coesão do tecido social e os mecanismos culturais que permitem estabilizar a população desempenham papel decisivo na determinação do estado de saúde dos adultos e da idade que tem probabilidade de morrer". (Illich, 1975, p.20).

Contudo, a propaganda veiculada pela ordem médica tenta, a todo custo, convencer a população da eficácia dos remédios e da necessidade do médico/cientista/salvador como produtor de saúde.

\section{A iatrogenia e o mito da ciência}

Fatores como a crença na ciência e no seu poder de expressar verdades inquestionáveis; a expropriação do indivíduo no que se refere ao seu saber sobre a saúde; a expansão industrial; a produção em larga escala de medicamentos e derivados; o distanciamento cada vez maior entre homem e natureza; a mídia a serviço do capital vendendo tudo a todos e a proliferação dos especialistas são alguns aspectos que afirmam a medicina de Panacéia.

A este respeito Illich (1975) sinaliza o quanto os atos médicos e programas de ação sanitária têm resultado "em fontes de nova doença: a iatrogênica" (p.14). Os efeitos iatrogênicos dos tratamentos, em geral invisibilizados, crescem proporcionalmente ao crescimento da utilização de remédios, substâncias químicas e tratamentos que não consideram a força vital do organismo. "Enfermidade, impotência, angústia e doenças provocadas pelo conjunto de cuidados profissionais constituem uma epidemia mais importante do que qualquer outra, e não obstante a menos reconhecida" (idem, p.14). A ação dos medicamentos, tratamentos e terapias pode ser compreendida na sua dupla face de atuação: a face 
"boa" dos medicamentos que ataca a doença, e a face "má" que ataca o doente sob o eufemismo de "efeitos colaterais".

A partir do que constatamos na nossa clínica, nos simpósios, congressos e demais encontros onde o tema é abordado, é assustadora a quantidade de novos sintomas produzidos pelas pessoas quando sob o efeito de medicamentos e tratamentos em geral. É inegável que os efeitos colaterais dos medicamentos provocam incontáveis sintomas e que esses são mais difíceis de serem tratados, pois se apresentam combinados com outros medicamentos e com a própria doença, para a qual o medicamento foi indicado. Neste processo, o curso da doença é alterado, produzindo novos sintomas. São utilizados, então, novos medicamentos que, combinados com os anteriores, produzem outros sintomas. Um círculo vicioso no qual é comum constatarmos a utilização de inúmeros medicamentos e terapêuticas para a mesma doença. A doença vai se complexificando e se cronificando. É comum, atualmente, uma pessoa tomar vários remédios por dia associados a tratamentos paralelos, terapias, e, mesmo assim, não se sentir bem.

A outra face da iatrogenia é o descrédito em si, o surgimento da apatia física e psicológica. A pessoa se sente mal, enfraquecida, incapaz e dependente. "A produção profissional de traumatismos psicológicos não é, portanto, uma exclusividade do psiquiatra: todo contato com a empresa médica expõe o paciente ao perigo de danos psíquicos" (Illich, 1975, p.36).

Apesar de recorrer a médicos, tratamentos, equipamentos e exames de última geração, muitas vezes o paciente segue se sentindo mal, fraco, desanimado e apreensivo, pois não consegue resolver o seu problema, que se agrava dia a dia, por conta do próprio tratamento. O que fazer, já que a ciência é incompetente para tratá-la? Quem mais poderá fazer isso? Talvez a homeopatia, a acupuntura, as terapias alternativas, uma "raizeira"? O processo é este: procurar por algum especialista, alguém que saiba mais sobre você do que você mesmo. Procurar pela mágica que ocorrerá através do comprimido certo, da terapia indicada, de alguma substância externa. Uma busca desesperada que leva o paciente de tratamento em tratamento, de especialista em especialista, de ilusão em ilusão.

Atualmente, prevenir é fazer exames periódicos, ir ao médico com frequência, visitar consultórios, analistas, acupunturistas. Não é preciso estar doente para se tornar um paciente. Prevenir torna-se fundamentalmente consumir, check-ups, medicamentos para acalmar angústias, fazer dormir, fazer acordar, novas dietas, exercícios para um corpo "sarado" bem ao gosto da estética vigente, antídotos que expurguem sinais de envelhecimento, e os "prazos de validade" do corpo (Santana, 2002). Vejamos uma vez mais o que nos fala Illich (1975) sobre esse tema: "A extensão do controle profissional a 
cuidados dispensados a pessoas em perfeita saúde é uma nova manifestação de medicalização da vida" (p.61).

Nesta direção, Foucault faz uma afirmação que vem ao encontro do que estamos problematizando, ou seja, a medicina como uma estratégia extensiva biopolítica.

\section{A medicina como instrumento de biopoder}

A corporação médica, a partir dos séculos XVIII/XIX, irá se imiscuir na intimidade da vida pessoal exercitando o que Foucault chamou de biopoder, ou seja, forma de controle via objetivação da vida das populações em todas as suas expressões molares e moleculares, ou seja, no seu aspecto visível e no campo virtual. Estabelecerá normas de conduta, realizará levantamento estatístico de nascimentos e mortes, coletará dados sobre número de filhos, escolaridade, trabalho, sexualidade, hábitos e costumes até então excluídos do campo da medicina. Neste registro "O que entra em jogo aqui já não é o direito à vida ou à saúde dos pacientes, membros de uma comunidade política, o que se converte em objeto de pesquisa é, em palavras de Foucault, o corpo espécie" (Capponi, 2004, p.449).

São diversas as formas de controle desenvolvidas na sociedade atual. $\mathrm{O}$ biopoder talvez expresse o controle mais abrangente ao qual 0 indivíduo se submete, pois é o controle não mais sobre este ou aquele aspecto da vida, mas sobre a vida na sua totalidade, do nascimento à morte. Conrad (2007) explicita como indícios do processo de medicalização da vida a construção de mecanismos e enunciados sustentados por diferentes racionalidades científicas que põem sob tutela médica eventos ou problemas da vida cotidiana.

Do ponto de vista biopolítico, os processos de intensificação da vida estão incondicionalmente conjugados aos processos de ativação das forças produtivas e de sua reprodução, pois o modo de produção capitalista, hoje, materializa-se não só em toda a sociedade e em todas as relações sociais, mas também, e, primordialmente, no governo da 'natureza humana' e da vida em sua virtualidade. Os afetos, o conhecimento, o desejo são fortemente incorporados ao atual regime de acumulação capitalista. (Neves \& Massaro, 2009).

\section{Vetor II - A Psicanálise: construção da neurose universal}

A psicanálise, que irrompeu na vida intelectual, social e artística do século passado como nenhuma outra força cultural, tem, inicialmente, a proposta de revolucionar a sociedade da época construída sobre as bases da razão. Ela irá descortinar a existência de outro mundo. Um mundo psíquico, até então desconhecido, que 
atribui ao inconsciente à mola mestra do agir humano: 'o homem não é senhor na sua própria casa.' (Freud, 1914/1979)

Dessa forma, a psicanálise adentrou o cenário cultural sinalizando para uma transformação que, a partir de Viena, iria disseminar-se por todos os importantes centros da Europa. Não duvidamos da influência da psicanálise na transformação da vida cultural e social da época. Entretanto, queremos seguir outras vias que entendemos terem sido criadas pela difusão da teoria e prática da psicanálise e, principalmente, a via que cria uma relação original entre analista/analisando, e que servirá para pensarmos a questão da saúde no contemporâneo.

Partimos da hipótese inicial de que antes do surgimento da psicanálise, vale lembrar, no início do século $X X$, as pessoas eram vistas ou como doentes mentais, ou como pessoas normais. Os doentes mentais eram tratados por métodos repressivos como a clausura e o confinamento, sendo a eles imputada a perda total de direitos e formas desumanas de tratamento. As pessoas consideradas normais não eram, até então, passíveis de nenhum tipo específico de tratamento.

Com o surgimento da psicanálise, as pessoas que apresentavam diversos tipos de sintomas considerados psíquicos, tais como certos graus de angústia, ansiedade e frustrações sem etiologia conhecida, passam a serem incluídas num outro regime de distribuição normalizadora: a classe dos neuróticos. Surge, aí, uma nova classe de doença: a neurose.

A produção/constatação/instauração desta verdade universal, gera a necessidade de tratamento da neurose, e num mesmo movimento produz o neurótico, alimentando um grande mercado de demandas para as práticas de saber/poder que em seus alinhamentos e conjugações disciplinares e biopolíticos se retroalimentam. Como se dá este processo?

Podemos pensar seu alinhamento no que se refere ao cuidado/tratamento/tutela a partir de um duplo golpe: um primeiro no qual somos ao mesmo tempo totalizados como neuróticos e individualizados na escuta psicanalítica de nossas neuroses, cujo foco nos produz como individualidades de nossa história pessoal/familiar. Um segundo alinhamento pode ser pensado quando somos ligados, pelo destino produzido no estatuto de verdade da neurose universal, a um aparelho produtor de normalização, docilização e tutela que se oferta como fonte inesgotável de acolhida às frustrações, sintomas e lida cotidiana com os impedimentos impostos pela realidade à "nossa natural busca do prazer".

"A psicanálise insinuou-se entre dois pólos, dizendo ao mesmo tempo em que somos todos loucos sem termos ar disso, e que temos aspectos de loucos sem sermos. Toda uma 
"psicopatologia da vida quotidiana"... ao descobrir entre dois pólos o mundo das neuroses, com integridade das faculdades intelectuais, e mesmo ausência de delírio, a psicanálise, nos seus primórdios conseguia uma operação muito importante: fazer passar por uma relação contratual-liberal toda uma série de pessoas que, até aí, pareciam estar excluídas dela (a "loucura" colocava todos os que atingiam fora de qualquer contrato possível). O contrato propriamente psicanalítico, um fluxo de palavras em troca de um fluxo de dinheiro, ia fazer do psicanalista alguém capaz de se inserir em todos os poros da sociedade ocupados por estes casos incertos". (Deleuze \& Parnet, 2004, p.106).

Questões de instabilidade emocional, ansiedade, inibições, dificuldade de adaptação social, problemas do cotidiano que poderiam ser enfrentados de outra forma, transformam-se em doença, neurose, e passam a ser tratadas pelos psicanalistas.

\section{Um testamento oneroso}

Ao escrever, em 1937, um dos seus últimos textos sobre psicanálise, A Análise Terminável e Interminável, Freud demonstra a sua inquietação com relação ao momento adequado do término da análise, e que, num outro sentido, também é a nossa: "A decisão do problema técnico de saber como acelerar o lento progresso de uma análise nos conduz a outra questão.... Sua análise não foi terminada ou ele nunca se analisou até o fim..." (Freud, 1975, v. 23, p. 250).

Além dessa questão levantada por Freud, outros dados podem melhor contextualizar a sua preocupação:

"(...) na década de 1920, um ou dois anos eram considerados suficientes; nas décadas 1930 e 1940, a norma eram dois a quatro anos; nas décadas de 1950 a 1960, quatro a seis anos; hoje em dia, seis a oito anos. Os casos que terminam formalmente - isto é, por assentimento mútuo entre analista e analisando - são relativamente raros. A maioria dos casos analíticos termina porque o paciente se muda para outra cidade, ou fica sem dinheiro, ou abandona impulsivamente a análise, ou concorda com o analista em que se chegou a um ponto de estagnação". (Malcolm, 2005, p. 165).

Freud (1978) dizia que para uma pessoa que sonha e lembra-se dos seus sonhos com certa facilidade, o que não seria muito anômalo, 0 
processo da autoanálise seria indicado, e ele próprio veio a empreendê-lo com algum sucesso. Diz ele:

"logo que me dei conta da necessidade de levar a efeito uma auto-análise, e o fiz com a ajuda de meus próprios sonhos ...., sendo ainda hoje de opinião que essa espécie de análise talvez seja o suficiente para uma pessoa que sonhe com freqüência e não seja muito anormal" (p.49).

\section{Análise: um modelo de dependência?}

Estamos construindo uma hipótese que, entre outras vicissitudes, a psicanálise intensifica e estende, em sua emergência como prática de saber-poder, a produção de uma relação mercadológica singular no cuidado ao psiquismo. A neurose foi criada ou descoberta pela psicanálise, valorizada, e simultaneamente foi criado um tipo específico de terapia para administrá-la. A remuneração foi colocada como condição sine qua non à análise. As sessões eram indicadas, de forma peremptória, em geral várias vezes por semana, meses, anos. Conclui-se, daí, que sem remuneração não é possível a análise e, com remuneração, essa pode transformar-se em atividade interminável. Esta relação será investida de um caráter modelar para um incontável número de tratamentos, principalmente as futuras psicoterapias criadas a partir da mesma lógica de produção da psicanálise: paciente/analista/remuneração.

Como afirmamos desde o início, nossas questões não se restringem ao setting psicanalítico, embora ele tenha muito de modelar. Tratase, isto sim, de problematizar as diversas formas de atendimento que vão desde a psicanálise passando pela clínica médica, psicoterapias, homeopatia e acupuntura a uma gama inumerável de terapias que trabalham nessa lógica tutelar e interminável.

Pensamos que a prática da auto-análise quando não restrita aos settings e/ou enquadres condicionantes de maior ou menor grau de anormalidade, tal como pensado por Freud, pode se constituir em outra saída, uma linha de fuga ${ }^{5}$ agenciada com movimentos de construção, apropriação e criação constante de si e do mundo.

\section{No entrecruzamento dos vetores: a mídia e os especialistas em você}

O mundo em meio ao qual construímos nossa existência, em maior e menor escala, produz desconfortos, instabilidades, estranhezas e sofrimentos. Somos atormentados por compromissos e desafios de estar sempre atualizados pela infinidade de informações produzidas 
cotidianamente pela mídia. Entre tantas questões que nos afetam pensamos no excesso de consumo, seja de mercadorias e/ou signos de prestígio, sucesso, estilos de vida. Pensamos também no despropósito do consumo individual ou coletivo e ainda predatório, que pode chegar ao ponto de colocar em risco de aniquilamento a humanidade e todo o planeta. Entretanto, seguimos consumindo sem problematizar efetivamente o que consideramos serem as nossas necessidades. Seguimos em uma verdadeira corrida olímpica em direção ao consumo, no qual o poder e a capacidade de consumir acabam sendo a medida de uma vida bem sucedida.

O investimento realizado através da mídia na produção do medo, angústia, pânico, depressão e seus "antídotos" são o novo objetivo do mercado da saúde. Segundo Soares \& Caponi, (2011) a "transformação do sofrimento em patologia, ou situação de risco em uma doença futura, com sua consequente medicalização, são marcantes na demanda atual de bem-estar e intolerância ao sofrimento alheio" (p.440).

Percebe-se, então, que o campo dos afetos e desejos é de riqueza inimaginável, "poços de petróleo" no mundo atual, como constataram os estudos de Conrad (2007) sobre as indústrias farmacêuticas e Soares e Caponi (2011) na pesquisa sobre o problema da Depressão: "O aumento das vendas de antidepressivos pela indústria farmacêutica é, paradoxalmente, proporcional ao aumento da depressão e ao aumento da prescrição de medicamentos voltados para doenças intermediárias" (p. 445).

A partir dessa perspectiva, podemos dizer que, na prática, hospitais, clínicas, postos e unidades de saúde, cursos de formação de especialistas, planos de saúde, laboratórios, atendimento médico, psicanalítico, psicoterápico, acupuntura, homeopatia, etc., têm produzido ações mais voltadas para processos de produção de doença e tutela dos doentes, que de ativação de saúde. Isso significa dizer, e é importante que fique claro, que não são as técnicas que atuam a favor ou contra a saúde, mas a lógica tutelar que vem sendo dominante na aplicação e consumo dessas técnicas. Estamos sinalizando para um desvio ético de atendimento à saúde que conduz os indivíduos ou pacientes a processos intermináveis de tratamento.

Pacientes que fazem cinco ou mais tratamentos ao mesmo tempo, outros que realizam o tratamento desde que nasceram, aqueles que encontraram o tratamento certo para o resto da vida, os que tomam inúmeros medicamentos diariamente.

A mídia dissemina a indústria da doença, as instituições também buscam o seu espaço no mercado, os especialistas estão ávidos de pacientes, e assim vai se construindo e naturalizando uma verdadeira compulsão coletiva, orquestrada por frases como: "você deve se tratar", "você merece o melhor tratamento", "você precisa dos melhores profissionais", "você merece o melhor hospital, plano de 
saúde, analista, acupunturista" etc. O processo de convencimento é ardiloso e o tratamento pressupõe sempre consumo, dispêndio, dependência. $O$ paciente, quer na psicanálise, quer nas mais diversas formas de atendimento a saúde, é sempre estimulado a acreditar que vai conhecer outro alguém que sorrateiramente o habita, um duplo em si, e mais, que esse outro alguém é melhor e mais interessante do que ele próprio. Ser outro é uma das síndromes do mundo contemporâneo descartável. E mais, ser outro artificialmente, através da (re) engenharia e da tecnologia da saúde.

As características que têm assumido contemporaneamente os encontros no campo da clínica dificultam, sobremaneira, os indivíduos a se indagarem sobre a lógica de consumo impressa nesses tratamentos. É a delegação de poder de tutela sobre a vida, que "em nome do cuidado" e "em nome da produção de saúde" acabam por desqualificar ou desconsiderar modos autônomos de soluções para expressões do ser denominando-as de doenças ou desequilíbrios.

\section{Linhas de fuga e a ética do cuidar}

A subjetividade, por nós entendida, como um processo coletivo de 'produção de $\mathrm{si}^{\prime}$, em constante engendramento, se faz em meio às configurações históricas e confrontos éticos-políticos que tecem nossos modos de estar nos verbos da vida (viver, pensar, trabalhar, formar, cuidar...), e ganha expressão e visibilidade nas práticas e modos nos quais, e pelos quais, tecemos, somos tecidos e afirmamos nos movimentos do real o cotidiano de nossos fazeres. Não estamos sem saída, mas precisamos de mais ousadia e criação para viver e afirmar em nós um devir revolucionário (Guattari, 1981), para construir linhas de fuga e tremores nas instituições e seus instituídos. Experimentar uma linha de fuga jamais significou fugir de algo, ao contrário disto implica fazer fugir o acontecimento para outro lugar. Implica um sair de si, a experimentação de vetores de dessubjetivação ou de 'desterritorialização' em nossos modos de existência.

Nossa aposta ético-política se faz na direção de que nossas interferências na produção, compreensão e reinvenção da realidade implicam uma torção metodológica que force, no pensamento, a abertura à porosidade de práticas e sentidos que (re) produzem a realidade para além, e aquém, das configurações e interpretações homogêneas nas quais se apresenta e é apresentada. É neste campo de imersão que as práticas de cuidado ganham consistência de intervenção, de intervir entre ações, experimentando os desafios cotidianos de invenção de novos territórios existenciais num contexto contemporâneo que se caracteriza por uma nova relação entre o poder e a vida. 
Já no título do presente artigo - "Encontros da Vida Nua nos Jardins do Capital" - trazemos a complexidade desta aposta buscando sinalizar que é em meio a esse espaço-tempo paradoxal do capitalismo contemporâneo, o único que conhecemos, que podemos avançar para pensar os processos de produção de cuidado na clínica. Uma clínica que evidencia a via ética que norteia qualquer clínica, qualquer técnica. Poderíamos dizer que é uma clínica que tem como premissa ser um instrumento facilitador da construção de uma vida nua, porque singular. Vida nua como ón haplôs: "simples, sem artifício, natural" (Houaiss, 2004), ainda que complexa. Vida como potência de criação que excede os modos de ser, incitando e insistindo na reinvenção desses modos em meio aos assujeitamentos que enfraqueçam a sua potência de diferir. Vida nua porque desprovida da necessidade de adereços, adjetivos. Uma vida substantiva que tem como direção ou modo de realização o fluir e o se desprender de tudo que a constrange.

Com este entendimento, tomamos uma direção diversa do entendimento de 'vida nua' proposto por Agamben (2007). Este autor parte do conceito de biopolítica desenvolvido por Foucault para pensar como se atualizam nas sociedades contemporâneas uma estrutura biopolítica fazendo uso da distinção, no grego, entre vida como zoé e bíos. Como zoé faz referência ao sentido da vida natural, do acontecimento primário, e como bíos refere a vida que incorpora direitos e obrigações no contexto político/social. Nesta perspectiva, ele irá indicar o caminho que alguns regimes políticos de exceção tomaram, criando um ciclo onde a vida nua, zoé, assume o caráter de bíos, com a inserção social e seus desdobramentos e, no limite, retorna ao estágio de zoé. Este retorno se dá quando a vida, então assumida como bíos, passa a sofrer profundos constrangimentos por parte desses regimes de exceção, reduzindo-a ao seu caráter vegetativo ${ }^{6}$. Assim, a biopolítica exerce o poder de manter os seres numa zona intermediária entre vida e morte, revertendo o que já foi bíos em zoé. Para Pelbart (2007), que avança na discussão da questão, o exemplo do muçulmano, prisioneiro dos campos de concentração, e o neomorto das salas de terapia intensiva encarnam a figura tradicional da vida nua. A partir deste enfoque, 0 que se vislumbra aqui é que a condição de sobreviventes, longe de se restringir aos exemplos acima, refere-se também ao efeito generalizado do biopoder nas sociedades ocidentais, democráticas e contemporâneas, produzindo uma vida residual e vegetativa também nas sociedades de consumo, no hedonismo de massa, na medicalização da existência.

Canguilhem (1990) nos indicou que a vida se afirma pela sua potência de criar normas, normatividade, e não por um assujeitamento a normas. Pensar a saúde como experiência de criação de si e de modos de viver é tomar a vida em seu movimento 
de produção de normas e não de assujeitamento a elas (Neves; Massaro, 2009). Seguindo com este autor na afirmação da vida como força auto-produtiva frente à infidelidade do meio usamos a noção de vida nua entendendo-a como potência de fruição, desapegada de tudo que a constrange, uma vida que, embora transite em todos os espaços, não se deixa capturar por eles, flui desviando dos constrangimentos em meio e entre o mundo e a vida encarnada em formas e pessoalidades. Uma vida intensiva que, em meio ao mundo atual, não está refém da cultura, da política em seus arranjos disciplinar e biopolítico, apesar de neles e por eles também transitar. Ao longo do artigo discutimos e enfrentamos questões com relação a um modo tutelar de produzir saúde que entendemos naturalizado no contemporâneo. Na medida em que íamos apresentando os vetores que canalizaram forças para esse tipo de produção (medicina e psicanálise), e que chamamos de assujeitada, apresentamos também, de forma explícita ou implícita, linhas de fuga que se alinham com o posicionamento de pensar/produzir saúde como um processo autônomo de autorregulação do humano.

Trata-se, então, de construirmos uma clínica que, atenta aos processos da vida tem, entre os seus objetivos, se fazer precisa e desnecessária. Uma clínica na qual qualquer entrada ou expressão instrumental a ser utilizada não tem maior ou menor importância, pois o que importa são as saídas que pode produzir. (Deleuze; Parnet 2004).

Aqui voltamos a Foucault, combinando vida e clínica, para lembrar o que ele diz sobre a ética de transformar a vida em uma obra de arte (Foucault, 1994) e pensar que esta pode ser afirmada na capacidade de construir encontros que fortaleçam a potência de vida e que a façam brilhar, cada vez mais, em nossos olhos. Uma clínica/arte produtora de devires, linhas de fuga, disruptora e libertadora dos aprisionamentos que transformam a vida nua em vida indigna de ser vivida, em vida/refém, despotencializada.

O que significa isso? Como ativar em nós essa vida nua? Quais os caminhos, preceitos, receitas que nos levam a isso?

Esse é o belo desafio proposto pela existência e para o qual desde já afirmamos não possuir resposta, a não ser a de saber que esses caminhos encontram-se em meio aos "minados" jardins do capital. Pensamos, também, que nesses caminhos há a arte das bifurcações e desvios que se agenciam a processos de afirmação das singularizações, das diferenças, num constante vir a ser.

Poderíamos dizer que aí está o plano de consistência de onde emanam as idéias de nosso artigo: um plano criado e sustentado pela convicção de que o humano é índice de inacabamento e, portanto, pode mais. Ingenuidade? Otimismo vazio e desencarnado? Afirmamos que não, pois sabemos dos muitos combates a empreender em nosso presente. No apêndice sobre Foucault, Paul Veyne (1978, p.181) diz 
algo que nos ajuda nessa direção: não se trata de "explicar as práticas a partir de uma causa única, mas a partir de todas as práticas vizinhas nas quais se ancoram. Esse método pictórico produz quadros estranhos, onde as relações substituem os objetos".

\section{Referências}

Agamben, G. (2007). Homo Sacer: O poder soberano e a vida nua. Belo Horizonte: Editora UFMG.

Canguilhem, G. (1990). O normal e o patológico. Rio de Janeiro: Forense.

Caponi, S. (2004). A biopolítica da população e a experimentação com seres humanos. Ciência \& Saúde Coletiva, 9, 445-455.

Conrad, P. (2007). The medicalization of society: on the transformation of human conditions into treatable disorders. Baltimore: Johns Hopkins Press.

Deleuze, G. (1992). Conversações. Tradução: Peter Pál Pelbart. São Paulo: Ed.34.

Deleuze, G. \& Parnet, C. (2004). Diálogos. Lisboa: Relógio D'Água Editores.

Escóssia, L. \& Kastrup, V. (2005). O conceito de coletivo como superação da dicotomia indivíduo sociedade. Psicologia em Estudo 10(2), 295-304.

Foucault, M. (1993). Vigiar e punir: nascimento da prisão. Petrópolis: Vozes.

Foucault, M. (1985). História da Sexualidade III- O cuidado de si. Rio de Janeiro: Edições Graal.

Foucault, M. (1989). Microfísica do poder. Rio de Janeiro: Graal.

Foucault, M. (1994). História da sexualidade II: o uso dos prazeres. Rio de Janeiro: Graal.

Foucault, M. (1999). Em defesa da sociedade: curso no Collège de France (1975-1976). São Paulo: Martins Fontes.

Foucault, M. (2006). O Nascimento da Clínica. Rio de Janeiro: Forense Universitária.

Foucault, M. (2008). Segurança, território, população. São Paulo: Martins Fontes.

Freud, S. (1969). Moisés e o Monoteísmo Esboço de Psicanálise e Outros Trabalhos: Análise Terminável e Interminável. In S. Freud. Obras Psicológicas Completas. Rio de Janeiro: Imago Editora LTDA. Freud, S. (1978). Cinco Lições de Psicanálise: a história do movimento psicanalítico: o futuro de uma ilusão, o mal-estar na civilização, esboço de psicanálise. São Paulo: Abril Cultural.

FREUD, S. (1914/1979). Sobre o narcisismo: uma introdução. In S. Freud. Obras completas. Rio de Janeiro: Imago Editora LTDA. 
Guattari, F. (1981). Revolução Molecular: pulsações políticas do desejo. São Paulo: Editora Brasiliense.

Houaiss, A. (2004). Dicionário Houaiss da Língua Portuguesa. Rio de Janeiro: Objetiva.

Illich, I. (1975). A Expropriação da Saúde: Nêmesis da Medicina. Rio de Janeiro: Editora Nova Fronteira.

Malcolm, J. (2005). Psicanálise a profissão impossível. Tradução de Vera Ribeiro. Rio de Janeiro: Relume Dumará.

Neves, C. E. A. B. (2002). Interferir entre desejo e capital. Tese de Doutorado em Psicologia Clínica. Pontifícia Universidade Católica de São Paulo, São Paulo, SP, Brasil.

Neves, C. E. A. B. \& Massaro, A. (2009). Biopolítica, produção de saúde e um outro humanismo. Interface. Comunicação, Saúde e Educação, 13, $503-514$.

Negri, A \& Hardt, M. (2001). Império. Rio de Janeiro: Record.

Nogueira, R.P. (2003). A saúde pelo avesso. Natal: Seminare Editora.

Orlandi, L. B. L. (2002). Que estamos ajudando a fazer de nós mesmos? In M. Rago, L. B. L Orlandi \& A. V. Neto. (Orgs.). Imagens de Foucault e Deleuze ressonâncias nietzscheanas (v. 1, pp. 217238). Rio de Janeiro: DP\&A.

Pelbart, P. P. (2007). Vida Nua, Vida Besta, Uma Vida. Trópico. São Paulo, Recuperado em 10 julho, 2007, de: <http://p.php.uol.com.br/tropico/html/textos/2792,1.shl>.

Santana, D. B. (2002). Transformações do corpo: controle de si e uso dos prazeres. In M. Rago; L.b.L.Orlandi \& A. Veiga-Neto. (Orgs.). Imagens de Foucault e Deleuze - ressonâncias nietzschianas ( $v$. 1, p. 99-110). Rio de Janeiro: DP\&A.

Soares, G. B. \& Caponi, S. (2011). Depressão em pauta: um estudo sobre o discurso da mídia no processo de medicalização da vida. Interface, 15(7), 437-446.

Veyne, P. (1978). Como se escreve a história (1971) e Foucault revoluciona a história. Brasília: Editora UNB.

\section{Endereço para correspondência \\ Donati Canna Caleri}

Asbamtho - Escola de Medicina Chinesa - Rua Ipiranga, 88 sobrado, Laranjeiras, CEP 22231-120, Rio de Janeiro - RJ, Brasil.

Endereço eletrônico: caleri-donati@ig.com.br

\section{Claudia Abbês Baêta Neves}

Universidade Federal Fluminense - Departamento de Psicologia - Campus Gragoatá - Rua Professor Marcos Waldemar de Freitas Reis, bloco O sala 212, São Domingos, CEP 24210-201, Niterói - RJ, Brasil.

Endereço eletrônico: abbes@luma.ind.br

Recebido em: 06/08/2012

Reformulado em: 01/11/2013

Aceito para publicação em: 09/12/2013

Acompanhamento do processo editorial: Deise Mancebo 


\section{Notas}

* Doutorando do Programa de Pós Graduação em Psicologia da Universidade Federal Fluminense - Niterói (RJ), Brasil. Mestrado no Programa de Pós Graduação em Psicologia na Universidade Federal Fluminense, Niterói (RJ) Brasil.

** Professora Associado I do Departamento de Psicologia e Programa de Pós Graduação em Psicologia da Universidade Federal Fluminense. Niterói (RJ), Brasil. Doutora em Psicologia Clínica pela PUC/SP(2002).

${ }^{1}$ Ivan Illich, em seu livro A expropriação da saúde: nêmesis da medicina, de 1975, foi um dos pioneiros em apontar os descaminhos da moderna medicina e sua sofisticação tecnológica. A este respeito ver as discussões realizadas por NOGUEIRA(2003).

${ }^{2}$ Para Illich a iatrogênese clínica está referida ao ato médico e a sua técnica; a iatrogênese social é o efeito social não desejado e prejudicial do impacto social da medicina (medicalização do orçamento, invasão farmacêutica, controle social pelo diagnóstico que etiqueta as diferentes idades humanas, dentre outros) e a iatrogênese estrutural que faz referência ao processo de delegação de elementos característicos da vida humana (como o significado da dor física, da morte e da doença), ao uso ilimitado da medicina. (NOGUEIRA, 2003).

3 Hades (em grego antigo: 'Aঠ̄s, transl. Hádēs) é o deus do submundo e das riquezas dos mortos. O nome Hades era usado frequentemente para designar tanto o deus quanto o reino que governa, nos subterrâneos da Terra.

4 Negri e Hardt (2001) afirmam o funcionamento do poder no capitalismo globalizado como uma nova soberania chamada Império. O império é sem limites e sem fronteiras em vários sentidos, desde o englobar a totalidade do espaço-mundo, apresentando-se como ordem a-histórica, eterna, definitiva, até a penetração na vida das populações, nos seus corpos, mentes, inteligência, desejo e afetividade. Ele se encarrega positivamente da produção e da reprodução da própria vida organizando a totalidade das atividades da população. O império, diferente do imperialismo, não está atrelado a uma entidade política ou nacional localizada, apesar de ter centros que se configuram na parcela de países mais ricos e com tecnologia de ponta, espalhados por todo o planeta.

${ }^{5}$ Linhas de fuga é um conceito construído por Gilles Deleuze e Félix Guattari ao pensar os grupos indivíduos e sociedade como um composto e entrecruzamento de linhas de força distintas, mas indissociáveis. Tal como as delimitações geográficas em suas composições de territórios políticos, econômicos e culturais, os indivíduos e seus modos de existência são produzidos nos agenciamentos com o que eles chamam de três tipos de linhas que definem inúmeras relações com o espaço e o tempo: de segmentaridade (ciclos binários e espaço estriado), linhas flexíveis (retiradas fragmentárias, limiares de redistribuição afetiva) e linhas de fuga (desterritorialização radical ligada à imprevisível criação de novos espaços-tempos, de agenciamentos institucionais inéditos). Estas últimas são linhas que, apesar de nos comporem, devem ser inventadas e traçadas na vida. A este respeito ver: DELEUZE; GUATTARI(1996), pp. 75-76.

${ }^{6} \mathrm{O}$ exemplo mais clássico, porém longe de ser o único, foi o que aconteceu com os judeus no período do regime nazista (1939/1945). As práticas político-subjetivas do Holocausto e do anti-semitismo produziram uma redução dos judeus à zoé, a uma vida nua. Uma "vida indigna de ser vivida", destituída de todo e qualquer direito e que, no relato de Agamben (2007), é referida pelo termo "muçulmano" ( $p$. 191). Esta referência visa afirmar uma generalização que extrapola a conotação puramente étnica, encarando os prisioneiros dos campos de concentração como verdadeiros cadáveres ambulantes. 